\title{
Hepatitis C virus infection
}

\author{
Michael Fralick MD, Jordan J. Feld MD MPH
}

See also www.cmaj.ca/lookup/doi/10.1503/cmaj.150612 and www.cmaj.ca/lookup/doi/10.1503/cmaj.150652

\section{Screening recommendations for hepatitis $\mathrm{C}$ vary by jurisdiction}

Hepatitis C virus (HCV) results in more lost years of life and more illness than any infectious disease in Ontario. ${ }^{1}$ Screening individuals born between 1945 and 1965 using an anti-HCV antibody test is currently recommended in the United States. ${ }^{2}$ A similar approach appears to be cost-effective in Canada and may replace the current practice of screening high-risk individuals (e.g., with a history of injection drug use, transfusion before 1992 or birth in an endemic country). ${ }^{3}$

\section{Chronic HCV infection develops in the majority of infected patients}

Hepatitis C virus affects 250000 to 400000 Canadians and may lead to progressive liver fibrosis. ${ }^{3}$ Chronic HCV infection develops in about $70 \%$ of patients exposed to the virus. ${ }^{5}$ A normal alanine transaminase level and/or a normal liver ultrasound does not rule out fibrosis. Fibrosis should be evaluated in all patients using newer noninvasive tools such as transient elastography and serum panels with biomarkers for fibrosis, or, when necessary, liver biopsy. ${ }^{6}$ Thrombocytopenia suggests severe fibrosis.

\section{References}

1. Kwong JC, Ratnasingham S, Campitelli MA, et al. The impact of infection on population health: results of the Ontario burden of infectious diseases study. PLOS ONE 2012;7:e44103.

2. Chou R, Cottrell EB, Wasson N, et al. Screening for hepatitis $\mathrm{C}$ virus infection in adults: a systematic review for the US Preventive Services Task Force. Ann Intern Med 2013;158:101-8.

3. Wong WWL, Tu HA, Feld JJ, et al. Cost-effectiveness of screening for hepatitis $\mathrm{C}$ in Canada. CMAJ 2015;187:110-81

4. Wong T, Lee SS. Hepatitis C : a review for primary care physicians. CMAJ 2006;174:649-59.

\section{Chronic HCV infection is curable}

New oral direct-acting antiviral agents (e.g., sofosbuvir/ledipasvir, sofosbuvir/ simeprevir and paritaprevir/ombitasvir/ dasabuvir) achieve high cure rates (> 90\%) with 8-24 weeks of welltolerated therapy. ${ }^{7}$ Direct-acting antivirals can be used alone or in combination with peginterferon plus ribavirin. The optimal regimen depends on $\mathrm{HCV}$ genotype, past treatment, medical comorbidities and the degree of liver fibrosis. Patients with undetectable levels of HCV RNA 12 weeks following treatment are cured of HCV. ${ }^{5}$ Like those who spontaneously clear the infection after exposure (about $25 \%$ ), cured individuals continue to test positive for anti-HCV antibodies for life, but are not protected from reinfection.

5. Myers RP, Ramji A, Bilodeau M, et al. An update on the management of chronic hepatitis $\mathrm{C}$ : consensus guidelines from the Canadian Association for the Study of the Liver. Can J Gastroenterol 2012;26:359-75.

6. Schiavon LL, Narciso-Schiavon JL, de CarvalhoFilho RJ. Non-invasive diagnosis of liver fibrosis in chronic hepatitis C. World J Gastroenterol 2014;20:2854-66.

7. Sulkowski MS, Gardiner DF, Rodriguez-Torres $\mathrm{M}$, et al. Daclatasvir plus sofosbuvir for previously treated or untreated chronic HCV infection. N Engl J Med 2014;370:211-21.
Chronic HCV infection is often asymptomatic, making the diagnosis challenging

Most patients with chronic HCV infection are asymptomatic. Symptoms may arise once cirrhosis develops, but this takes years to occur. ${ }^{4}$ Patients with a positive anti-HCV antibody test require polymerase chain reaction testing for $\mathrm{HCV}$ RNA levels to confirm chronic infection. ${ }^{5}$

The current threshold for starting treatment depends on the extent of liver fibrosis

Direct-acting antivirals are expensive. The extent of liver fibrosis is currently the major determinant for initiating therapy because treatment is most cost-effective in those with advanced or advancing fibrosis who are at greatest risk of future complications. ${ }^{4}$ Patients with extrahepatic manifestations of HCV (e.g., glomerulonephritis or cryoglobulinemic vasculitis) should be prioritized for urgent therapy. ${ }^{5}$

Competing interests: Jordan Feld reports grants and/or personal fees from AbbVie, Bristol-Myers Squibb, Gilead Sciences, Janssen, Merck, Theravance, Boehringer Ingelheim and Santaris. No other competing interests were declared.

This article has been peer reviewed.

Affiliations: Department of Medicine (Fralick, Feld) and Toronto Western Hospital Liver Clinic (Feld), University of Toronto, Toronto, Ont.

Correspondence to: Michael Fralick, mike.fralick @mail.utoronto.ca

CMAJ 2015. DOI:10.1503/cmaj.140290 